HETEROCYCLES, Vol. 87, No. 2, 2013, pp. 303 - 306. @ 2013 The Japan Institute of Heterocyclic Chemistry Received, 25th November, 2012, Accepted, 17th December, 2012, Published online, 25th December, 2012 DOI: $10.3987 / C O M-12-12638$

\title{
SYNTHESIS OF NOVEL THIOPHENE-FUSED 1,1'-BIAZULENE DERIVATIVE BY THE REACTION OF AZULENO[1,2-b]THIOPHENE WITH $N$-IODOSUCCINIMIDE
}

Taku Shoji, ${ }^{\text {a* }}$ Erika Shimomura, ${ }^{\text {a }}$ Yuta Inoue, ${ }^{\text {a }}$ Mitsuhisa Maruyama, ${ }^{a}$ Atsuyo Yamamoto, ${ }^{a}$ Kunihide Fujimori, ${ }^{a}$ Shunji Ito, ${ }^{b}$ Masafumi Yasunami, ${ }^{c}$ and Noboru Morita ${ }^{\mathrm{d}}$

${ }^{a}$ Department of Chemistry, Faculty of Science, Shinshu University, Matsumoto, 390-8621, Japan. E-mail: tshoji@shinshu-u.ac.jp

${ }^{\mathrm{b}}$ Graduate School of Science and Technology, Hirosaki University, Hirosaki 036-8561, Japan

${ }^{c}$ Department of Materials Chemistry and Engineering, College of Engineering, Nihon University, Koriyama 963-8642, Japan

d Department of Chemistry, Graduate School of Science, Tohoku University, Sendai 980-8578, Japan

\begin{abstract}
Novel thiophene-fused 1,1'-biazulene derivative was prepared by the reaction of azuleno[1,2-b]thiophene with $N$-iodosuccinimide. The electronic properties of the new 1,1'-biazulene derivative obtained by the reaction were characterized by CV, DPV, and UV/Vis spectroscopy.
\end{abstract}

$N$-Iodosuccinimide (NIS) is one of the efficient reagents for the iodation of organic compound. Thus, in the azulene chemistry, several 1-iodoazulene derivatives have been prepared by the reaction with NIS. ${ }^{1}$ Recently, Abe et al. have reported the generation of 1,1'-biazulene and 1,1':6',1"-terazulene derivatives by the reaction of ethyl 2-aminoazulene-1-carboxylate with NIS. ${ }^{2}$ They proposed a radical mechanism for the oxidative-coupling reaction quoted our previous reports. ${ }^{3,4}$ Several synthetic methodologies of 1,1'-biazulenes have been reported in the literatures. ${ }^{5}$ However, in most cases the methodologies require metal catalyst, high temperature reaction, and/or longer reaction period. Thus, the reaction reported by Abe et al. could become one of the innovative synthetic methodologies from the viewpoint of metal-free synthesis of 1,1'-biazulene derivatives. Azulene-fused heterocycles have attracted the interest owing to its unusual chemical properties. ${ }^{6}$ Thus, preparation and reactivities of a number of azulene-fused heterocycles have already been revealed by many research groups. ${ }^{7}$ However, $1,1^{\text {'-biazulene derivatives }}$ 
fused by heterocycles have never been reported so far, although several synthetic methodologies of 1,1'-biazulene derivatives have been found in the literatures as described above.

Herein, we report the synthesis of thiophene-fused 1,1'-biazulene by the reaction of azuleno[1,2-b]thiophene (3) with NIS. The electronic property of the new 1,1'-biazulene derivative obtained by this reaction was also characterized by CV, DPV, and UV/Vis spectroscopy.

Azuleno[1,2-b]thiophene (3) was prepared using a similar procedure reported by Fujimori and Yasunami et al., ${ }^{8}$ starting from methyl 1,2-dihydro-9-(azuleno[1,2-b]thiophene)carboxylate (1) as shown in Scheme 1. We have examined the reaction of $\mathbf{3}$ with NIS to obtain iodine derivative of $\mathbf{3}$. In this case, we have expected a usual iodation of azulene ring by the electrophilic substitution reaction to afford a 1-iodoazulene derivative as described in the literatures. However, contrary to the expectation, we found the reaction produced novel 1,1'-biazulene derivative $4^{9}$ in $74 \%$ yield (Scheme 1). The reaction of 3 with $N$-bromosuccinimide (NBS) and $N$-chlorosuccinimide (NCS) did not afford 4, but lead to the decomposition of $\mathbf{3}$. Although the reaction of 1,2-dihydro-9-azuleno[1,2-b]thiophene (5) with NIS was also examined under the similar reaction conditions, only decomposition of the starting compound was observed instead of the formation of the corresponding 1-iodoazulene or 1,1'-biazulene derivative 6. Thus, this homo-coupling reaction might be specific reactivity for 3 with NIS. Previously, we have reported the facile preparation of the 1,1'-biazulene derivatives by the treatment of 1-azulenyl methyl sulfoxides with Brønsted acid. ${ }^{3}$ Therefore, the formation of $\mathbf{4}$ might be attributable to NIS, which should act as an oxidant for the generation of $\mathbf{4}$, although detail of the reaction mechanism is currently unclear.

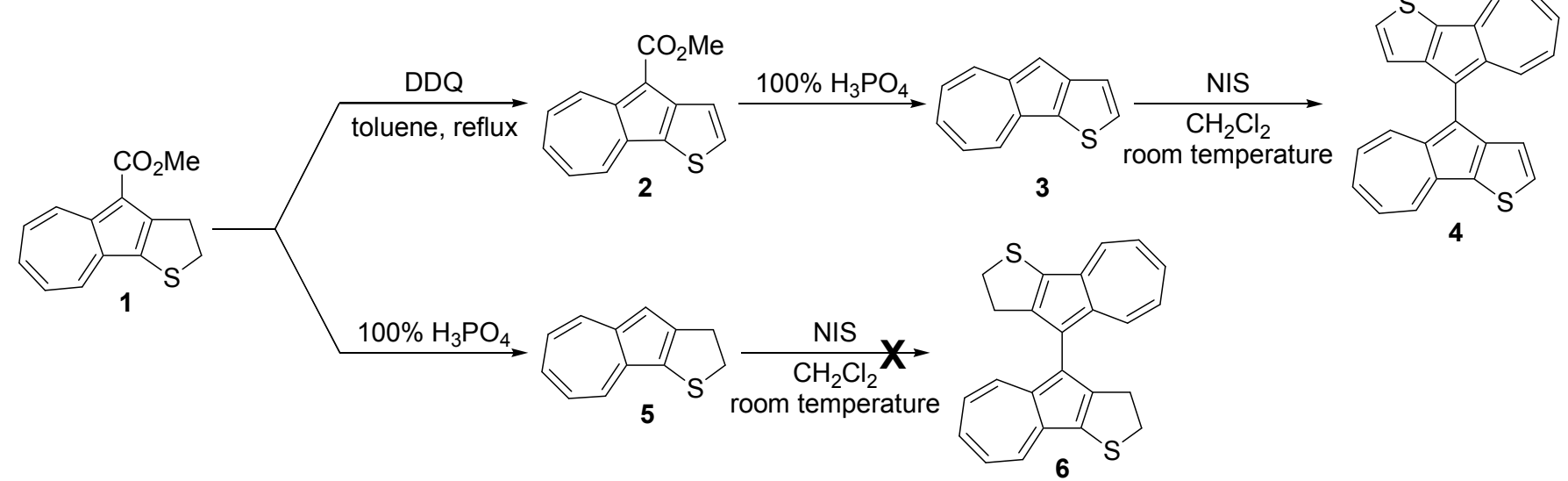

Scheme 1. Synthesis of thiophene-fused 1,1'-biazulene derivative 4.

UV/Vis spectra of 3 and 4 in $\mathrm{CH}_{2} \mathrm{Cl}_{2}$ are compared in Figure 1. Compounds 3 and 4 in $\mathrm{CH}_{2} \mathrm{Cl}_{2}$ showed characteristic weak absorption bands in the visible region arising from the azulene system. Although the longest absorption band of $\mathbf{4}$ displayed larger absorption coefficients than that of $\mathbf{3}$, the absorption maxima were observed at almost the same wavelength. The similarity of the absorption maxima of $\mathbf{3}$ and 4 suggests less effective conjugation due to the low planarity of the two azulene rings of 4 . To clarify the 
electrochemical properties, the redox behavior of $\mathbf{3}$ and $\mathbf{4}$ was also examined by CV and DPV. 1,1'-Biazulene derivative 4 exhibited a reversible and following an irreversible oxidation waves (Figure 2 ), of which potentials were identified at $+0.22 \mathrm{~V}$ and $+0.49 \mathrm{~V}$ by DPV. These results could be attributable to the instability of dicationic species generated by electrochemical oxidation owing to the electrostatic repulsion of two azulenium ions. In the case of the electrochemical analysis of $\mathbf{3}$, an irreversible oxidation wave $(+0.42 \mathrm{~V})$ was observed by DPV, due to the generation of instable radical cationic species. Thus, the 1,1'-biazulenyl structure of $\mathbf{4}$ should stabilize a radical cationic species, rather than that of $\mathbf{3}$.

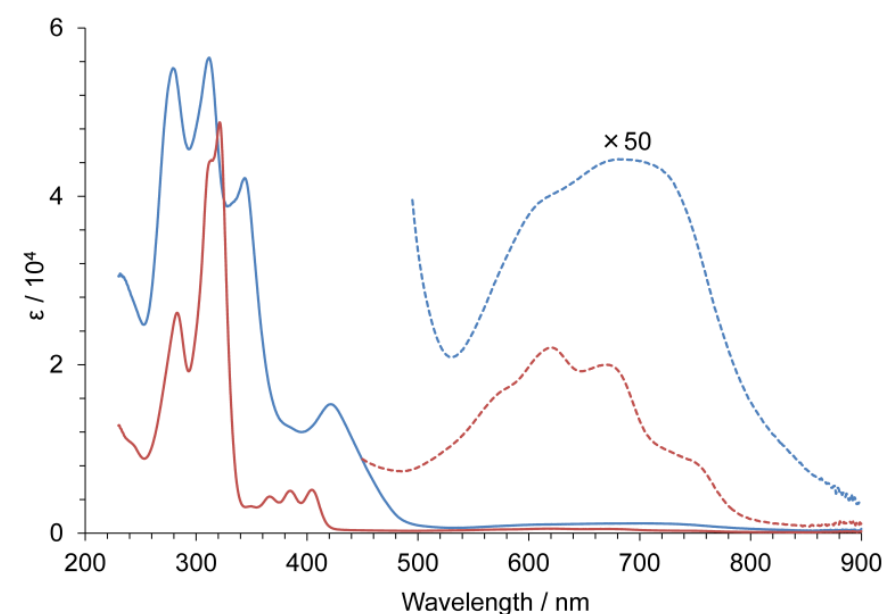

Figure 1. UV/Vis spectra of $\mathbf{3}$ (red line) and $\mathbf{4}$ (blue line) in $\mathrm{CH}_{2} \mathrm{Cl}_{2}$.

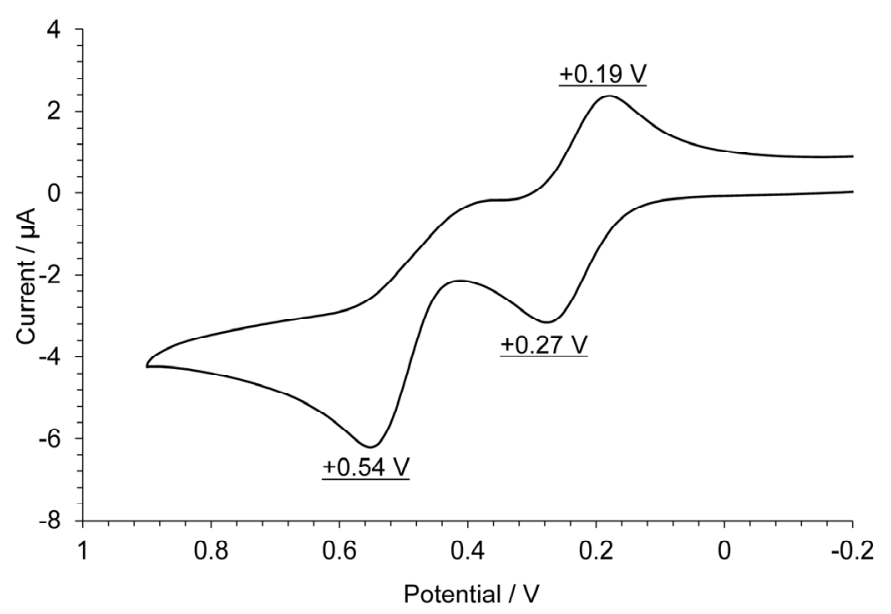

Figure 2. Cyclic voltammogram of 4 in $(1 \mathrm{mM})$ in benzonitrile containing $\mathrm{Et}_{4} \mathrm{NClO}_{4}(0.1 \mathrm{M})$ as the supporting electrolyte; scan rate $=100 \mathrm{mVs}^{-1}$.

In conclusion, we have described generation of novel thiophene-fused 1,1'-biazulene derivative 4 by the reaction of 3 with NIS, as well as the electronic properties of $\mathbf{4}$ which were characterized by CV, DPV, and absorption spectroscopy. Although the scope of this reaction is unclear up to now, these results should be an important finding in the chemistry of azulene, because NIS is frequently used as a reagent for the iodination of azulene derivatives.

\section{ACKNOWLEDGEMENTS}

This work was partially supported by a Grant-in-Aid for Research Activity Start-up (Grant No. 22850007 to T.S.) from the Ministry of Education, Culture, Sports, Science and Technology, Japan.

\section{REFERENCES (AND NOTES)}

1. (a) K. H. H. Fabian, A. H. M. Elwahy, and K. Hafner, Eur. J. Org. Chem., 2006, 791; (b) N. C. Thanh, M. Ikai, T. Kajioka, H. Fujikawa, Y. Taga, S. Ogawa, T. Zhang, H. Shimada, Y. Miyahara, S. 
Kuroda, and M. Oda, Tetrahedron, 2006, 62, 11227; (c) T. Shoji, S. Ito, K. Toyota, M. Yasunami, and N. Morita, Chem. Eur. J., 2008, 14, 8398.

2. M. Hyoudou, H. Nakagawa, T. Gunji, Y. Ito, Y. Kawai, R. Ikeda, T. Konakahara, and N. Abe, Heterocycles, 2012, 86, 233.

3. (a) T. Shoji, S. Ito, K. Toyota, M. Yasunami, and N. Morita, Tetrahedron Lett., 2007, 48, 4999; (b) T. Shoji, J. Higashi, S. Ito, K. Toyota, M. Yasunami, and N. Morita, Eur. J. Org. Chem., 2008, 1242.

4. 1,1'-Biazulene derivatives were also obtained as a by-product under the $\mathrm{Tf}_{2} \mathrm{O}$-activated heteroarylation of 1-azulenyl sulfides. (a) T. Shoji, K. Okada, S. Ito, K. Toyota, and N. Morita, Tetrahedron Lett., 2010, 51, 5127; (b) T. Shoji, Y. Inoue, and S. Ito, Tetrahedron Lett., 2012, 53, 1493.

5. (a) T. Morita and K. Takase, Bull. Chem. Soc. Jpn., 1982, 55, 1144; (b) M. Iyoda, K. Sato, and M. Oda, Tetrahedron Lett., 1985, 26, 3829; (c) A. C. Razus, J. Chem. Soc., Perkin Trans. 1, 2000, 981; (d) A. C. Razus and C. Nitu, J. Chem. Soc., Perkin Trans. 1, 2000, 989.

6. G. Fischer, Adv. Heterocyclic Chem., 2009, 97, 131.

7. (a) D.-L. Wang and K. Imafuku, Heterocycles, 2001, 54, 647; (b) K. Imafuku and D.-L. Wang, Heterocycles, 2002, 58, 405; (c) H. Matsuo, K. Fujimori, A. Ohta, A. Kakehi, M. Yasunami, and T. Nozoe, Heterocycles, 2003, 61, 271; (d) M. Nishiura, I. Ueda, and K. Yamamura, Heterocycles, 2007, 74, 951; (e) S. Ito, T. Okujima, S. Kikuchi, T. Shoji, N. Morita, T. Asao, T. Ikoma, S. Tero-Kubota, J. Kawakami, and A. Tajiri, J. Org. Chem., 2008, 73, 2256.

8. (a) K. Fujimori, T. Fujita, K. Yamane, M. Yasunami, and K. Takase, Chem. Lett., 1983, 11, 1721; (b) S. Ito, T. Kubo, M. Kondo, C. Kabuto, N. Morita, T. Asao, K. Fujimori, M. Watanabe, N. Harada, and M. Yasunami, Org. Biomol. Chem., 2003, 1, 2572.

9. Typical procedure: To a solution of $3(368 \mathrm{mg}, 2.00 \mathrm{mmol})$ in $\mathrm{CH}_{2} \mathrm{Cl}_{2}(10 \mathrm{~mL})$ was added $N$-iodosuccinimide $(540 \mathrm{mg}, 2.40 \mathrm{mmol}$ ) at room temperature. The resulting mixture was stirred at the same temperature for $10 \mathrm{~min}$ under an Ar atmosphere. After the solvent was removed under reduced pressure, the crude product was purified by column chromatography on silica gel with $\mathrm{CH}_{2} \mathrm{Cl}_{2}$ to give $4(271 \mathrm{mg}, 74 \%)$ as brown crystals. $\mathrm{Mp} 255.0-257.0{ }^{\circ} \mathrm{C}\left(\mathrm{CH}_{2} \mathrm{Cl}_{2} / \mathrm{MeOH}\right) ; \mathrm{MS}(\mathrm{EI})$ : $m / z(\%)=366(100), 332(19), 319(8), 183(13) ;{ }^{1} \mathrm{H}$ NMR $\left(500 \mathrm{MHz}, \mathrm{CDCl}_{3}\right): \delta_{\mathrm{H}}=8.41(\mathrm{~d}, 2 \mathrm{H}, J=$ $10.0 \mathrm{~Hz}, \mathrm{H}-8$ ), 8.12 (d, 2H, $J=10.0 \mathrm{~Hz}, \mathrm{H}-4), 7.77$ (d, 2H, $J=5.0 \mathrm{~Hz}, \mathrm{H}-\mathrm{Th}), 7.50$ (t, 2H, $J=10.0$ Hz, H-6), 7.31 (d, 2H, J=5.0 Hz, H-Th), 7.19 (t, 2H, $J=10.0 \mathrm{~Hz}, \mathrm{H}-7$ ), 6.96 (t, 2H, $J=10.0 \mathrm{~Hz}$, H-5) ppm; ${ }^{13} \mathrm{C}$ NMR (125 MHz, $\left.\mathrm{CDCl}_{3}\right): \delta_{\mathrm{C}}=153.18$ (C-2), 137.74 (C-8a), 136.45 (C-4), 136.35 (C-6), 134.12 (C-3a), 132.77 (C-Th), 130.84 (C-8), 130.12 (C-1), 123.30 (C-7), 121.87 (C-5), 119.86 (C-Th), 117.35 (C-3) ppm. 